\title{
Research of Localization of Foreign-invested Hotels in China
}

\author{
Furong Tian
}

Tourism College, Kunming Univesity, Kunming, 650214,China

\begin{abstract}
Keywords: foreign investment; foreign-invested hotels in China; localization; shortcomings; strategy
\end{abstract}

\begin{abstract}
Since the reform and opening up, foreign-invested hotels gradually entered China with a rapid development. This thanks to its strong financial support and excellent hotel culture as well as localization transformation according to China's specific national conditions. This paper briefly describes connotation of localization and positive function of localization of foreign-invested hotels. Aiming at the some shortcomings, we can implement the localization strategy to improve service quality from several prospects like post establishment, talent training, marketing management and hotel culture construction.
\end{abstract}

\section{Introduction}

As global economic integration, multinational companies to enter the Chinese market one after another and domestic enterprises also try to global. For example, Kempinski Hotel plans to open 12 hotels in 2014, of which are 4 hotels in China. If an enterprise wants to achieve internationalization, it should implement localization strategy in target country. It is a necessary requirement for development strategy of foreign-invested hotels in China. Currently, foreign-invested hotels in China have encountered some difficulties in localization process, including talent, marketing management and localization of hotel culture construction. Through localization of operating management, foreign-invested hotels in China can understand market needs and develop strategic deployment in line with local conditions, and then it will win in in competition with local enterprises.

\section{Theoretical study on the localization of the hotel}

\section{i. Localization meaning}

Localization, a new marketing concept, refers to all the activities of the enterprise should focus on the consumer instead of pay attention to interests of businesses. Enterprise standard shall be combined with regional conditions to adapt different needs of consumers. In order to play advantage of localization, Foreign-invested hotels in China shall improve hotel's humanistic culture, consider products and design concept to meet needs of local customers. Each international hotel that wants to open up a new market shall seize the minds of consumers and let customers with different cultural backgrounds recognize and accept same products so that it can capture the market more stable. The process of localization refers to that multinational companies apply production mode, selling concept and personnel management approach to economy of host country.

Only foreign brands implement localization can enter Chinese market. Only by improving overall localization will promote internationalization of multinational corporations. Therefore, an enterprise must realize localization to achieve internationalization. A key issue in development and implementation of localization strategy is how inherit the traditional strengths of the brand and in line with consumer preferences through combination of Chinese culture.

\section{ii. Positive function of localization of foreign-invested hotels in China}

First is to adapt to China's national conditions to obtain multi-support. Foreign-invested hotels in China make a success in the long run and get the praise, which are the result of market test and selection as well as correct and reasonable of its management and business philosophy. Moreover, their management model has also been extended in many other countries. If foreign investors want to open the Chinese market, they must investigate China's actual conditions, communicate and cooperate with government departments, investors, develop good management mode, fully develop 
and utilize human resources. Chinese relevant local governments and other parties give support to construction of foreign-invested hotels in China, because it can improve service and management level, increase employment opportunities, etc..

Second is to help create hotel features according to local condition. Overall model of hotel management is almost same, but different in specific management operation. Climatic environment is different due to vast territory, large populations and geographic position in China. Hotels shall understand its market position and shall reform and perfect level of the localization according to level of differentiation. To create a distinctive foreign-invested hotel in China can enhance and strengthen the competitiveness of the brand by using of existing resources and conditions.

The reform measures of localization could improve image of foreign-invested hotels in China and shoe its characteristics and improve recognition and credibility of market and consumers. If foreign-invested hotels in China could cultivate local talent along with the economic globalization, it will recruit people of the host country to command and management companies. Hence, it can show their inclusive of the hotel group, international image of the enterprise, characteristic management to the world. Foreign-invested hotels in China should put aside ethnic differences prejudice and recruit local management personnel as well as establish friendship and trust with government and people of host country to improve their credibility.

Third is to improve overall efficiency of the hotel brand development. Support by many parties could promote localization progress and bring overall efficiency to operation. For example, they can recruit local people to save labor costs, cooperate with owner to advertise and expand hotel market, promote their own brand image. If local government gives support in site selection, investment, construction, tax, it can greatly improve the hotel's brand image, enhance development effectiveness.

\section{Problems and shortcomings in localization process of foreign-invested hotels in China}

\section{i. Lack of high level of local management personnel and limitation of marketing channels}

Although the hotel employed a large number of domestic talent, it still lack of local talent who serves as senior manager. This makes daily operation of hotel blocked. Meanwhile, this phenomenon reflects bad relationship between hotel management mode and operating philosophy and local conditions as well as hinders association marketing chain, leading to difficulties in the construction of the hotel marketing network and unable to complete relationship localization. In contrast to other countries, there is almost no relationship concept. But this concept in China is very important. The hotels could obtain more convenience and useful information with government relations; get opportunity of dissemination and promotion with media relations; advertise its brand more smoothly with channel relations. In this regard, Jinjiang Group and The Ritz-Carlton and other hotels do not have too much competitive advantage compared with some local hotels.

\section{ii. Focus on talent employment and overlook talent cultivation in localization}

Many foreign-invested hotels in China only recruit intern to save labor cost. The enterprises only focus on human employment and overlook job training for employees, especially newly graduated intern who may be the power source of hotel future development. At the same time, there are high employee turnover in this field. If the hotel carries out personnel training, the employees may not be long in this hotel. Once the employee go to other hotel will be a new competitor for this hotel. Thus, taking into account the long-term interests of the hotel, staff training should be carefully chosen. To train all employees are unlikely. But hotel can train and guide some capable students as reserve force.

\section{iii. Localization of Marketing Management}

There are some problems during localization of marketing and management of foreign-invested hotels in China. First, for the area with deep traditional concept, they could not change marketing method and still adopt traditional marketing method. Secondly, the existing relationship marketing appears degradation. Therefore, the marketing manager should fully consider current various marketing methods and build effective relationships with public relations and domestic relationships. Finally, they should not overstate ability of a few people and ignore the team 
cooperation when they manage marketing team and individuals. The marketing requires cooperation and concerted effort of all staff. The marketing process requires cooperation and joint efforts of all staff.

\section{iv. Eager to rapid expansion of localization with weak characteristic creation}

Some hotels are anxious to achieve quick success and get instant benefits, increase office number as well as expand market share in the early opening. But it does not play its original features and combine local culture. For the area with high-star hotels, such as hotels in Sanya, the hotels have no local features and competitive advantage. However, localization process requires foreign-invested hotels in China to combine local characteristics and cultural with original characteristics, which could bring innovation and improvement in hotel rather than abandon the original features.

\section{Strategies}

\section{i. There is no position limits for local senior management personnel}

Most foreign-invested hotels in China mainly appoint its own people as senior management staff. Even if some staff of host country serves as senior staff, there is little promotion for them. If the one want to a higher position, he or she must have strong social and personal relationships within the group. Obviously, the local senior employees do not have this condition. By this time, he or she will consider job-hopping to seek perfect opportunity for development and improve their social values and promotion. The hotel could set aside some senior management positions for local staff who understands that they have ranks. When local employee acts as chairman or general manager in foreign-invested hotel in China, the localization of talent concept can be really realized.

\section{ii. Invest capital to train local talent}

Many foreign-invested hotels in China learn the experience like "Great hotel relies on the excellent staff”. So they spend a lot of money to carry out talent training, include online training, on-the-job training and so on. Some hotels with strong strength also cooperate with institutions to cultivate staff or establish their own training institutions.

The hotels advocate comprehensive training methods, for example, senior leaders can implement irregular job rotation policy to become an all-round talent. It also could set up trainee programs for capable staff and staff who can serve as senior staff. All the excellent staff and fresh graduates within group can apply for training opportunities or online study. The purpose of training is to improve employees' ability, which has innovative model for employees than simple labor remuneration. It also can promote sustainable development of employees. In this sense, training is part of benefits.

\section{iii. Rational and effective use of relationship marketing and enhanced internal marketing}

Relationship marketing refers to a communication and exchange process between enterprises and consumers, competitors, suppliers, government agencies and other parties. Harmonious conversation and cooperation of two parties can improve relationship and get a win-win through. The key point is that establish and perfect relationship with these parties.

China is in transition from tradition to modern. Relationship is a kind of indispensable resource organization in social development. The implementation of localization strategy of relationship can help foreign-invested companies in China to achieve success, which also makes Chinese government and people trust them. So multinational corporations can implement following strategies: to establish good relations with senior government, to focus Chinese education and sports, to help China Western Development and to participate public benefit activities.

The localization of passenger source is language communication and emotional communication, while it reduces the advantage of passenger source and operation mode. At this point, the advantages of Chinese employees will be highlighted. Hotel managers should pay attention to this phenomenon. It can attract customers from the perspective of Sino-foreign parties in common, such as culture, beliefs, customs and other similarities. The hotel shall give some incentives to Chinese managers and marketing personnel to advertise and establish sales network with region, business and customers. The same feeling between hotel and customers can enhance communication and contact with each other and improve mutual trust. This kind of credibility mechanism can promote 
staff in other departments to sell products by mobilizing their social relationships. However, the premise of this credibility mechanism is that the staff has high satisfaction of hotel.

\section{iv. To emphasize hotel culture characteristics in localization process}

To demonstrate their cultural level and to show their superiority can improve hotel culture characteristics. The most representative of hotel culture is to add CIS identification in product details. In the localization process, Kempinski Group does the best. Kempinski combines Chinese culture with Western culture, which brings good visual effect with weak in sensuous culture. It is not grand as lobby of Shangri-La, has no French romance like Sofitel and no understated luxury like Ritz Carlton.

Facing fierce competition of hotels with many advantages, the hotel shall show its own hotel culture and create a suitable brand with local characteristics. Performance is as following. Hotels design building and select suitable theme according to national and local characteristics. The hotels shall define their market identity by use of geographical advantages and combination of essence of history and culture and carrying forward era characteristics. It uses personalized construction to show distinctive cultural background. To create a unique atmosphere by color, vocal music can improve the guest for perception of national characteristics and local culture. For micro design, it can integrate culture and aesthetic concepts into hall, rooms, floors, walls and roofs and carefully arrange each element to make guest felt profound cultural connotation of hotel.

\section{Conclusion}

The foreign-invested hotels in China shall combine Chinese market conditions and adapt to needs of Chinese customers as well as conduct localization transformation to realize rapid development in China. Meanwhile, we must clearly recognize two-sides of same coin. Localization is no exception, which is also a double-edged sword. If used properly, it can improve service quality and promote development. Otherwise, it will get a bad result. That is to say, we must analyze and research the problems in localization process and play active role of localization process, so that the foreign-invested hotels in China will get better development.

\section{References}

[1] Tian Wangjun. Localization Strategy of International Hotel Group [J]. Journal of Beijing City University ,2013,04:100-103.

[2] Zhu Zun (Newspaper Reporter of East China Travelers). Apply Technology to Brand by Soft Power [N]. East China Travelers,2008 -01-22008.

[3]Tang Jinchun. Localization Development Research of Chinese Transnational Corporation. [J]. Special Economic Zone,2007,09:197-199. 